http://www.jfas.info

\title{
THE EFFECTIVENESS OF COMMUNICATION SKILLS AND EFFECTIVE DIALOGUE ON MARITAL SATISFACTION AND COMMITMENT OF YOUNG COUPLES
}

\author{
M. S. Moghadasi ${ }^{1}$ and M. Mohammadipour, ${ }^{2, *}$ \\ ${ }^{1}$ Department of Counseling, Quchan Branch, Islamic Azad University, Quchan, Iran \\ ${ }^{2}$ Department of Psychology, Quchan Branch, Islamic Azad University, Quchan, Iran
}

Published online: 15 June 2016

\begin{abstract}
The purpose of this study is analyzing the effectiveness of communication skills and effective dialogue on marital satisfaction and commitment of young couples. The research plan was the trueexperiment pre-test, post-test experimental and control groups. The statistical population was consisted of all couples (married less than 5 years) attending ARAMESH counseling clinic in the city of Gorgan in the second half of 2015. The research sample was selected among those couples, who volunteered to participate in educational and therapeutic sessions and randomly divided into two groups; experiment group (10 couples) and control group (10 couples). The effective training communication skills for the experimental group was conducted in 8 sessions of group counseling for 90 minutes and no training for control group. The research questionnaires were Afrooz Marital Satisfaction Scale (AMSS) and marital Dimensions of Commitment Inventory (DCI) of Adams and Jones (1977).
\end{abstract}

Author Correspondence, e-mail: mmohamadipoor@yahoo.com doi: http://dx.doi.org/10.4314/jfas.v8i2s.169 
The findings showed that training communication skills and effective dialogue have effect on marital commitment and satisfaction. On the other hand, according to Chi Eta contribution, it can be stated that training communication skills and effective dialogue explained $97 \%$ of the variance of couples marital commitment and satisfaction. Other findings showed that trainingcommunication skills and effective dialogue have effect on couples' satisfaction. On the other hand, according to Chi Eta contribution, it can be said that training communication skills and effective dialogue can explain $95 \%$ of the variance in satisfaction of couples. Other findings showed that training communication skills and effective dialogue have effect on marital commitment. On the other hand, according to Chi Eta contribution, it can be stated that training communication skills and effective dialogue explained $92 \%$ of the variance of couple's marital commitment. Since training communication skills and effective dialogue was desirable and effective for marital satisfaction and commitment, we recommend the implementation of this method in other samples to improve couple relations and develop new strategies in other words, encouraging families to provide new measures to improve family performance.

Keywords: Training communication skills and effective dialogue; marriage satisfaction, marriage; commitment; young couples.

\section{INTRODUCTION}

- Marriage is the pillar of a family, so it is defined by legal and religious relationship that men and women join to participate for an eternal life. Marriage and family formation has numerous intentions in diverse communities. In Islam these targets and incentives are listed as follows: creating a center of comfort and relaxation for men and women, maintaining chastity, friendship, affection, love, making balancein human existence, providing physical and mental health, freedom from loneliness, helping each other and having a child or children and healthy growth and development (Afrooz, 2008).

- According to many scholars, healthy communities has been established from healthy families and when the family includes healthy and productive environment is friendly 
and warm relations and interpersonal interaction, it can lead to growth of family members (Gholamipour and Abedi, 2011; Moein, Abasi, Jahedi and Dastgheib, 2011). The healthy family gives healthy people over to the community but dysfunctional family is the source of many problems in society and if we do not try to improve the family, social problems will increase day by day (Satir, 1972).

- Therefore, to achieve a healthy society, apparently relies on healthy families and it conditions on having people realize that having mental health and proper relationship with each other is necessary. The health of family members and their relationship undoubtedly will have positive effects on the community and it can be said that it has an important effect on family function and its direct impact on the performance of community (Samani and Ahmadi, 2011; Abangah, 2011).

- Studies in different cultures suggest that psychological and spiritual dissatisfaction and repulsion is the main root of spouse aversion, the spouse conflict and divorce and separation and vice versa, mutual attraction of partners ensure the mental and sensual feeling, relaxed and happy experience between spouses. In fact, marital satisfaction as close interpersonal relationships that allow people to be admitted, valued, respected and be loved, and to have the opportunity of mutual relations (Afrooz, 2006).

- Hawkins and Booth (2005)know marital satisfaction as feeling of happiness, satisfaction, and joy when all aspects of their marriage are considered by the husband or wife.Marital satisfaction is overall and mental assessment of the individual of the nature of marriage and the degree of satisfying needs, expectations and desires. Satisfaction is an attitudes variable. So it is considered as a personal attributes of a couple. According to the definition, marital satisfaction is actually a positive and joyful attitude that a couple has from different aspects of their marital relationship. In studies of Riahi, Aliverdinia and Bahramikakavand (2007) not meeting expectations of spouses, involvement of other, education and age differences and differences in ideas and Zargar and Neshatdoust(2007) communication problems, drug addiction, family intervention, psychological disorders are presented. Emotional and physical deprivations caused by the husband have effect in reducing the level of marital 
satisfaction and quality of couple life (Berdit, Brown, Urbach and Ms. Ilvan, 2010). Lawner and Bradbury (2010) had reported nervousness, chronical stress, low self-esteem and violence and finally dramatic reduction of marital satisfaction in gradual process of married life. They also showed that the couple benefit from a similar pattern in marital relationships and lifestyle that has same marital satisfaction.

- Bagarouzi (2001) showed that a lack of intimacy can cause conflicts, reducing marital satisfaction and emergence of emotional and psychological problems. In studies of Riahi, Aliverdinia and Bahramikakavand (2007) not meeting expectations of spouses, involvement of other, education and age differences and differences in ideas and Zargar and Neshatdoust (2007) communication problems, drug addiction, family intervention, psychological disorders are presented. As well as the research of Aviram, Hamburger (2005); Hashemi Mohammad Abad et al (2014) showed that the lack of efficient relations can lead to in infidelity which is aserious factor of instability in marital life. The factors causing instability in marriage, in research of Ghiasi, Moein and Rousta (2010) are not meeting the expectations of the spouse, husband's violence, dishonesty and educational and age differences. The different theories, considers marital turmoil is caused by wrong beliefs and communication theory, conflict in the couple's relationship is a result of inadequate communicating skills and the inability to effectively solve the problems (Nichols \& Schwartz, 1998).

- There are several approaches to improve couple relations. One of these methods is educating effective dialogue. This method is based on learning principles and especially is derived the McMaster model. McMaster model (1987) of family functioning model is a systematic model with clinical orientation of family functioning which determines the structural and organizational characteristics of families and important exchange patterns between family members (Kitner, 1996). McMaster aspects of family functioning variables include; problem solving, role, emotional responsiveness, emotional involvement, behavior control. The way of effective dialogue is one of training programs of marital relationship skills to couples. The basic assumption of this approach is that some special and vital communication 
skills to improve intimate relationships have not learned or forgotten (Halford and Moore, 2000). In this approach, focus is on increasing awareness of themselves and their partners, offering speaking and listening sharper and more accurate skills to send and receive messages, the emphasis on behavioral and attitudinal aspects of conflict resolution and communication and communication techniques to apply these skills (Miller et la, 2000). The important issue in this approach is determining the quality of the relationship and how to discuss them. In this regard, with the introduction of the cycle of awareness, the individual plan that helps identifying and developing awareness on the problems (Jacobsky, 2004). Research findings indicate compatibility of couples participating in these skills (Burnham, 1984; Busiki, 1982; Russell et al., 1984). Joaning (2009) also reported that the training effective dialogue in long term and stable on compatibility, reducing violence and increase and improve their skills were lead to intimacy of couples.

- Improve communication between couples seems necessary to prevent trouble and to have a satisfying and happy relationship. In general, today's models and different approaches have emerged to improve and enrich the lives of the couple and their relationship. Most of the treatments need attention of couples before facing problems to improve and build communication skills. These are psychological-training approaches which emphasize prevention and some of them include methods such as: strengthening the relationship, productive programs of marriage, the practical application of skills related to intimate relationships, preventive program and improving communication and focus on couples who still do not have experienced a major communication problem (Foroughan Far, 2006). Enriching method is one of the methods used to promote marital relations. Enriching is a movement to grow rich relationship and to strengthen the relationship through the establishment of goals leads to marriage. Enriching communication approach is an approach that integrated mental behavior views and communication systems in the family. This view has emphasized the importance of understanding people's beliefs about the cause of problems and helps clients learn skills that enable them to solve problems. In summary, skills that 
are taught in this approach are the provision of basic needs such as family, love, affection, belonging, trust, loyalty, security and pleasure. Compassionate sensitivity can be the most important factor in improving security and validate the relationship between couples and constructive intimacy and healthy environment for personal growth, the therapist plan first helps clients feel that they are being understood and then helps them to understand their problems more clearly and then realize that by learning the specific skills will help them work together to solve problems (Akordino, 1990, quoting the Soca, 2005; Jurnee, 2002; Jurnee, 2005). The enrichment programs are educational services which are designed to enhance and enrich the relationships between people, especially families. The program aims to increase the psychological and emotional satisfaction in close relationships and emotional and cognitive well-being of participants. These programs will include discussion and rational concepts and act at a cognitive level on concepts and ideas. A basic belief is that lack of understanding or misunderstanding the relationship undermines our performance, helps our mutual understanding of ourselves and people close to us one of the main objectives is to increase enrichment approach. According to enriching communication approach, rich relationships are those in which people have developed a great capacity for their understanding and transferring it. The goal is not only to increase capacity but also using it to improve past injuries, and effective action to deal with failures of life in the present and in the future. When the relationship enhancement skills are taught, it becomes as a permanent part of the treasures of individual's behavior and if necessary, can be used. This approach helps people to act beyond repositioning; they reinforce the ability of individuals to do things differently. Behavioral patterns changed after enriching communication skills and are replaced by more efficient ways (Nazari, 2007).

- With an overview to studies, it seems that marital satisfaction and couples loyalty in stable life of couples is impossible to be ignored. Therefore with regard to what was stated; the main purpose of this study was to evaluate the effectiveness of communication skills and effective dialogue on marital satisfaction and commitment 
of young couples. So according to what was said, it raises this main question that: Does communication skills and effective dialogue have effects on marital satisfaction and commitment of young couples?

\section{METHODOLOGY}

- The research plan was the true experiment pre-test, post-test experimental and control groups. The statistical population was consisted of all couples (married less than 5 years) attending ARAMESH counseling clinic in the city of Gorgan in the second half of 2015. The research sample was selected among those couples, who volunteered to participate in educational and therapeutic sessions and randomly divided into two groups; experiment group (10 couples) and control group (10 couples). The effective training communication skills for the experimental group was conducted in 8 sessions of group counseling for 90 minutes and no training for control group.

Table 1. The content of training sessions of effective dialogue and communication skills

First session introduction, setting basic communication, familiarity with its own positive and negative behavioral traits and analysis

Second session Teaching understanding of self and others (understanding yourself and people around you) training communication skills, speaking and negotiation skills as the first fundamental skills, modeling skills for members, giving assignment

Third session Self- expression skills, empathy skills, modeling skills for members, giving assignment

Fourth session Reviewing assignments of previous session, conflict resolution skill as a fourth fundamental skills, modeling skills for members, giving assignment

Fifth session Reviewing assignments of previous session, Teaching effective listening skills, explaining and practicing listening skills (attention, 


\begin{tabular}{ll}
\hline & pointing, inviting, summarizing and asking questioning), \\
& preparation and facilitation and modeling skills for members, giving \\
& assignment \\
\hline Sixth session & Reviewing assignments of previous session, Marital conflict \\
& (determining the nature and basis of conflicts and coping strategies), \\
& changing their skills training, modeling skills, giving assignment \\
\hline Seventh session & Reviewing assignments of previous session, Reviewing learned \\
& skills, teaching transfer and generalization skills, giving assignment \\
\hline Eighth session & Reviewing assignments of previous session, teaching maintenance \\
& and continuation of skills training, closing meetings, performances \\
& after test, determine the time for following up
\end{tabular}

\section{Data collection tools and research questionnaires are:}

- 1- Afrooz Marital Satisfaction Scale (AMSS): The questionnaire is designed by Afrooz and Ghodrati (2011) to evaluate marital satisfaction. It has 110-items. To design the questionnaires, the researchers based on conducted interviews and consultations with couples prepared the primary form of this scale that has 57 questions in 2010. In each item, they provided the content which is related to marital satisfaction. After standardization of the reliability and validity of the questionnaire it was reduced to 51 items. Each of the questions are graded by Likert method as 4-point continuum for strongly disagree $=1$, disagree $=2$, agree $=3$ and strongly agree $=4$ scores. The more scores a person takes in a test indicate higher marital satisfaction. To calculate the concurrent validity, concurrent with the implementation ofAfrooz satisfaction scale of couple, Enrich marital satisfaction questionnaire was performed on 60 couples. The correlation between Afrooz satisfaction scale of couple with Enrich marital satisfaction questionnaire were 0.431 at the level of $(p<0.001)$ is significant. Internal consistency coefficients 0.95 for the entire instrument showed that the optimal scale has been validated and is applicable for the couple satisfaction. He also showed 
that the reliability coefficient of test-retest of 0.79 indicates high internal consistency of this scale. Test-retest reliability coefficient within twenty days of the 60 couples, was 0.79 at the level of $(\mathrm{p}<0.05)$ was significant (Afrooz and Ghodrati, 2011).

\section{- 2- Dimensions of Commitment Inventory (DCI):}

- The question measures the commitment of spouse toward their spouse and marriage and its dimensions, this questionnaire is designed by Adams and Jones (1977) for research purposes and measures three aspects of marital commitment, which included; personal commitment, moral commitment and obligational commitment. Adams and Jones in 6 researches in order to obtain validity and reliability of the questionnaire performed it on married, single and divorced people and in this study the correlation of each question with the total score was meaningful and high. Adams and Jones calculated the reliability of the scale of the questionnaire: personal commitment 0.91 , moral commitment 0.89 and obligational commitment 0.86. The research also calculated reliability coefficients of all scales using Cronbach's alpha in this way; personal commitment 0.79 , moral commitment 0.80 and obligational commitment 0.82. The answer the questions on a 5 Likert scale (strongly agree to strongly disagree) is scored from 1 to 5 and higher score on this scale means higher marital commitment.Scores range from 44 to 220 .

\section{FINDINGS}

- To analyze the effect of training communication skills and effective dialogue on marital commitment and couple satisfaction, multivariate analysis of covariance was used and the results is as follows:

Table 2. Multivariate tests

\begin{tabular}{ccccccc}
\hline Tests & Value & F & $\begin{array}{c}\text { Hypoth } \\
\text { esis df }\end{array}$ & Error df & Sig. & $\begin{array}{c}\text { Partial Eta } \\
\text { Squared }\end{array}$ \\
\hline Pillai's trace & $\mathbf{0 / 9 7}$ & $\mathbf{5 3 2 / 5 1}$ & $\mathbf{2 / 0 0 0}$ & $\mathbf{3 3 / 0 0 0}$ & $\mathbf{0 / 0 0 0}$ & $\mathbf{0 / 9 7 0}$ \\
\hline Wilks' lambda & $\mathbf{0 / 0 3}$ & $\mathbf{5 3 2 / 5 1 8}$ & $\mathbf{2 / 0 0 0}$ & $\mathbf{3 3 / 0 0 0}$ & $\mathbf{0 / 0 0 0}$ & $\mathbf{0 / 9 7 0}$ \\
\hline
\end{tabular}




\begin{tabular}{ccccccc}
\hline Hotelling's trace & $32 / 27$ & $532 / 518$ & $2 / 000$ & $33 / 000$ & $0 / 000$ & $0 / 970$ \\
\hline Roy's largest root & $32 / 27$ & $532 / 518$ & $2 / 000$ & $33 / 000$ & $\mathbf{0 / 0 0 0}$ & $\mathbf{0 / 9 7 0}$ \\
\hline
\end{tabular}

- As it can be seen four covariance tests of Pillai's trace, Wilks' lambda, Hotelling's trace and Roy's largest root were calculated. The significance level of four tests $(0.000)$ is less than 0.05 , which represents the difference between at least one dependent variable (marital commitment and couple satisfaction) in experiment and control groups. In other words, minimal training of communication skills and effective dialogue has effect on one of the dependent variables (marital satisfaction and couple's commitment). Therefore, the hypothesis is confirmed with $95 \%$ confidence. On the other hand due to Chi Eta contribution, it can be said that training communication skills and effective dialogue explained the $97 \%$ of the variance of marital commitment and couple's satisfaction.

- The covariance analysis to examine the effect of training communication skills and effective dialogue on marital commitment is presented in Table 3:

Table 3. Univariate analysis of covariance test of marital commitment

\begin{tabular}{|c|c|c|c|c|c|c|c|}
\hline $\begin{array}{l}\text { Dependent } \\
\text { variable }\end{array}$ & $\begin{array}{l}\text { Changin } \\
\text { g source }\end{array}$ & $\begin{array}{l}\text { Sum of } \\
\text { Squares }\end{array}$ & $\mathrm{df}$ & $\begin{array}{l}\text { Mean } \\
\text { Square }\end{array}$ & $\mathrm{F}$ & Sig. & $\begin{array}{c}\text { Partial Eta } \\
\text { Squared }\end{array}$ \\
\hline Marital & Contrast & $5730 / 10$ & 1 & $5730 / 1$ & $408 / 16$ & $0 / 000$ & $0 / 923$ \\
\hline commitment & Error & 477/319 & 34 & 14/039 & & & \\
\hline
\end{tabular}

- According to the table above, the significance level (0.000) of F-test and post-test in marital commitment is less than 0.05 , therefore it can be concluded that training communication skills and effective dialogue has effect on marital commitment. Therefore, the hypothesis is confirmed with $95 \%$ confidence. On the other hand due to Chi Eta contribution, it can be said that training communication skills and effective dialogue explained the $92 \%$ of the variance of marital commitment and couple's satisfaction. 
- The covariance analysis to examine the effect of training communication skills and effective dialogue on couple's satisfaction is presented in Table 4:

Table 4. Univariate analysis of covariance test of couple's satisfaction

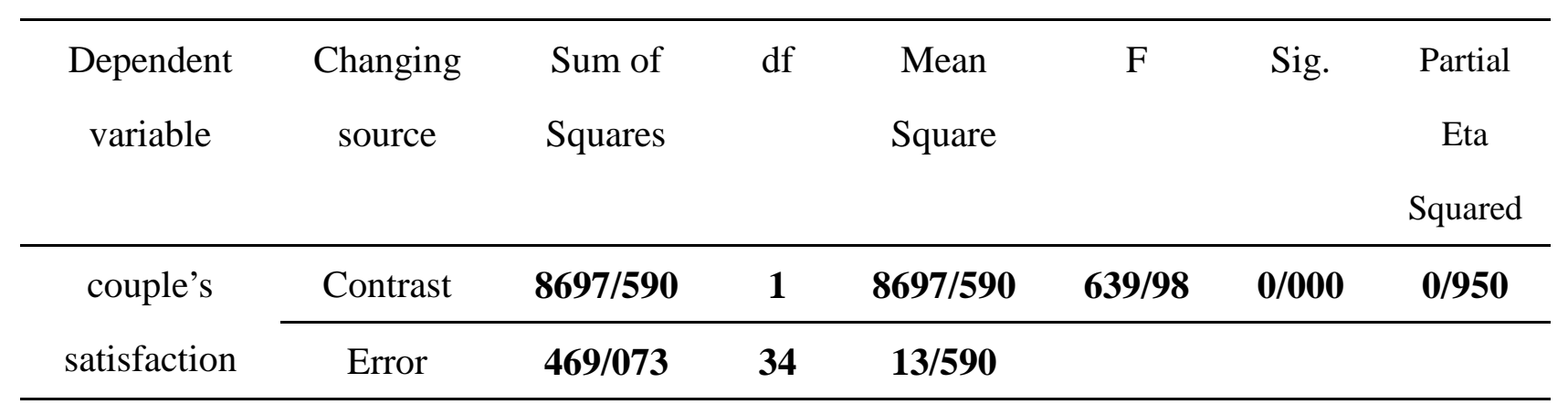

- According to the table above, the significance level (0.000) of F-test and post-test in couple's satisfaction is less than 0.05 , therefore it can be concluded that training communication skills and effective dialogue has effect on couple's satisfaction. Therefore, the hypothesis is confirmed with $95 \%$ confidence. On the other hand due to Chi Eta contribution, it can be said that training communication skills and effective dialogue explained the $95 \%$ of the variance of couple's satisfaction and couple's satisfaction.

- The mean scores of dependent variables in the pre-test and post-test scores of the control and the experimental group is as follows:

Table 5. Estimates

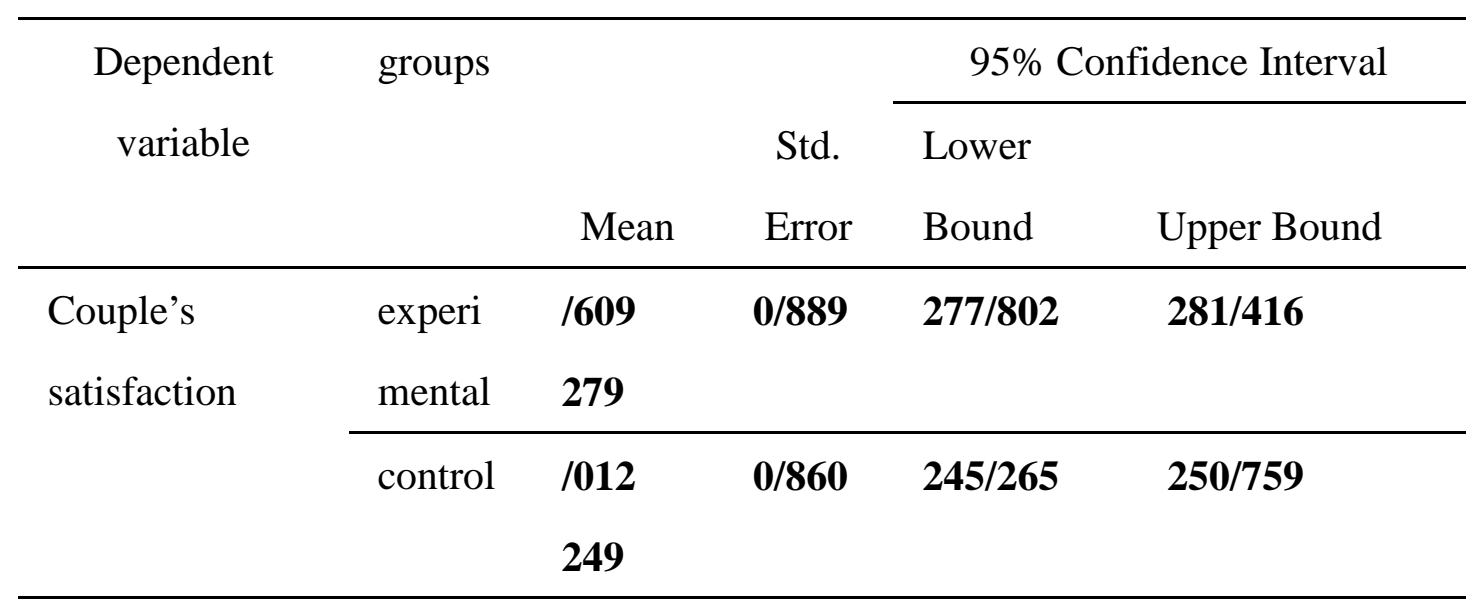




\begin{tabular}{lccccc}
\hline Marital & experi & $/ 782$ & $0 / 904$ & $162 / 945$ & $166 / 618$ \\
commitment & mental & 164 & & & \\
\cline { 2 - 6 } & control & $/ 947$ & $0 / 874$ & $138 / 172$ & $141 / 723$ \\
& & 139 & & & \\
\hline
\end{tabular}

- As it can be seen, in couple's satisfaction variable the mean score of experimental group is 279.679 and the mean score of control group is 249.012 which is about 30 points more than mean scores of control group. In other words, training communication skills and effective dialogue has effect on couples' satisfaction.

- In marital commitment variable the mean score of experimental group is 164.782 and the mean score of control group is 139.947 which is about 25 points more than mean scores of control group. In other words, training communication skills and effective dialogue has effect on marital commitment.

\section{DISCUSSION AND CONCLUSION}

- Marriage is the most exciting and the most stressful major life event of each person. Achieving a healthy society is obviously depending upon a healthy family relations and the realization of having people subject to mental health and having good relations with each other. Thus the normalization couples relation, undoubtedly will have positive effects on the community and it can be said that family performance have significant direct effect on community performance (Samani and Ahmadi, 2011, Abangah, 2011).

- Several factors have reduced the commitment and marital instability and rising divorce rates and separation of the couple's marriage. One of the most important factors which can be traced to the decline in marital satisfaction is the commitment to a married life can be influenced by the decrease in marital satisfaction. Numerous research studies on the effectiveness of psychological intervention in marital satisfaction and commitment and in this study we discussed teaching communication skills and effective dialogue. Enrichment programs can be linked to psychological and emotional satisfaction in close relationships, and cognitive emotional welfare. 
- The findings showed that training communication skills and effective dialogue has effect on couples' satisfaction. On the other hand, according to Chi Eta contribution, it can be said that training communication skills and effective dialogue can explain $95 \%$ of the variance of couple's satisfaction. These findings are consistent with studies of Afrooz (2006), Aliakbari (2012), Pourmeidani, Nouri and Shafti (2014), Riahi, Aliverdinia and BahramiKakavand (2007), Zargar and Neshatdoust (2007), Ahmadi, Nabipou, Kimyai and Afzali (2009) and Birdyt, Brown, Auerbach and Mac Aiello (2010), Dave Stewart (2012), Lavner and Bradbury (2010), Meltzer and McNulty (2010), Blue, Brenda, Brown and Ragsdel (2008), Botzer and Campbell (2008), Kramer (2012), Finney (2012), Lopez, Riggs, Pollard and Hook (2011), Brezniak and Wishman (2014), Byers (2015), Hawkins and Booth (2005). In explanation for this finding can be said that marriage is the origin of the family life cycle (Waring, 2013) And based on the Goldenberg definition (2008, quoted by Spencer, 2011) family is a subculture that is based on shared history, theories and internal perception of the world and shared objectives between its members and has a deep and multi-layered relationship. People are tied in such a system, through loyalty and powerful emotional, stable and mutually attachments (Monadi, 2006). Understanding the importance of intimate relationships and marriages show something that has been recommended by many people and it is a factor that will guarantee satisfaction, happiness and survival of the family (Sarookhani, 1996). Waring (2010) believes that opportunities to create intimacy between spouses are the most important factors in the normal functioning of the family. Therefore, the quality and quantity of intimacy between spouses is determining the environment and performance of the family. The concept of couple's satisfaction is mixed with marital agreements. Marital agreements are a description of the proper relationship between husband and wife (Yazdanparast and Nouhi Tehrani, 2012). There agreement between the spouses indicate the consolidation and reaffirming the rules, relationships and roles of marriage, which enables people to express their feelings, participate in planning and decision making and hopefully cooperate to solve their problems (Bagarouzi, 2001). In relationship with high marital 
agreement, both couples understand the behavior that their needs and expectations are met and there is nothing to interfere in their relationship (Yazdanparast and Nouhi Tehrani, 2012).In successful marriages, exchange and meet the expected needs of marital intimacy is strengthening the loving relationship between them as much as we can say that the basic principle in successful marriage is creating intimacy between couples (Bagazouri, 2001). On the other hand, family therapists believe that, knowing intimacy means the sense of awareness of diversity in family structures (Refahi and Moghtaderi, 2013). Sanderson \&Karetsky (2009) believe those who pay more attention to their spouses' concerns and seek for their emotional support have more skill to resolve the conflicts. Greeff\&Malherb (2001) observed a significant relationship between sexual intimacy and agreement between spouses. The results of Zarepour and Asoudeh (2011) showed that intimacy and mutual constructive communication pattern are the best predictors of mental health. The study of Cal, Paul, Tubro and Haas (2010) showed that family performance hashigh predictive powerof trust between family members and trust also has great power to influence the formation of intimate relationships between its members.Aslani, Sayadi and Amanolahi (2013) observedpositive and significant relationship between secure attachment as a predictor of intimacy and family performance.

- Other findings showed that communication skills training and effective dialogue have effect on marital commitment. On the other hand, according to Chi Eta contribution, it can be stated that communication skills training and effective dialogue explained $92 \%$ of the variance of couple's marital commitment. These findings are consistent with Sanayi (1996), BahramiKhundabi (2004) Lindsey and Olievotely (2007), Johnson (1997), Eta (1999) and Adams and Jones (1999), Schneider (1987), Stewart (1995), Neselz andTedchi (2001), and Stewart (1995). To explain these findings, we can say that marriage is a manifestation of love and affection within the framework of acceptable community, in fact, marriage is the human response to the need to love and to be loved (Sanaei, 1996). Successful marriage has 3 pillars of commitment, attractions and understanding and, in fact, marital commitment is the strongest and 
most consistent predictor of marital relationship quality and stability (Mosko, 2009). Lifelong commitment to marriage, loyalty to spouse, strong moral values, and respect for spouse as a best friend and commitment to sexual fidelity are features of satisfying marriages more than 20 years (Lindsy and Olivetely, 2007). Marital commitment is a guess where people have long-term view on their marriage, have dedication to their relationship to maintain and strengthen the solidarity and unity and stay with their spouses even when they are not rewarding marriage (Harmon, 2005). Although the commitment or intention to continue the relationship, often is considered as overall structure; it is clearly divided into 3 types (Johnson, 1997; Eta, 1999, Adams and Jones, 1999). The third type of commitment includes: a) a commitment to a spouse (personal commitment), based on the desire to stay in the relationship b) a commitment to marriage (religious or moral obligation associated with social obligations and responsibilities) and c) the mandatory commitment by entrapment in a relationship because of the costs and problems in the termination of that bond (Johnson, 1997; Eta, 1999, Adams and Jones, 1999).

\section{How to cite this article:}

Moghadasi M S and Mohammadipour M. The effectiveness of communication skills and effective dialogue on marital satisfaction and commitment of young couples. J. Fundam. Appl. Sci., 2016, 8(4S), 2095-2109. 